What We Learned from Mediated Embodiment Experiments and Why It

\title{
Should Matter to Policymakers
}

\author{
Laura Aymerich-Franch $^{1 *}$, Eduard Fosch-Villaronga ${ }^{2}$ \\ ${ }^{1}$ Pompeu Fabra University \\ ${ }^{2}$ Microsoft Cloud Computing Research Center and Center for Commercial Law Studies (CCLS) \\ at Queen Mary University of London, United Kingdom \\ *Correspondence to: \\ Laura Aymerich-Franch \\ Roc Boronat, 138 \\ 08018 Barcelona (Spain) \\ laura.aymerich@gmail.com
}


Abstract: When people embody a virtual or a robotic avatar, their sense of self extends to the body of that avatar. We argue that, as a consequence, if the avatar gets harmed, the person embodied in that avatar suffers the harm in the first person. Potential scenarios involving physical or psychological harm caused to avatars gives rise to legal, moral, and policy implications that need to be considered by policymakers. We sustain that the prevailing distinction in law between "property" and "person” categories compromises the legal protection of the embodied users. We advocate for the inclusion of robotic and virtual avatars in a double category property-person as the property and the person mingle in one: the avatar. This hybrid category is critical to protecting users of mediated embodiment experiences both from potential physical or psychological harm and property damage. 


\section{What We Learned from Mediated Embodiment Experiments and Why It Should Matter to Policymakers}

Mediated embodiment (ME) is the technologically induced illusion of experiencing the body of a virtual or robotic avatar as if it was the own body (Aymerich-Franch, 2018). Three subcomponents define the illusion of ME (Kilteni, Groten, \& Slater, 2012; Longo, Schüür, Kammers, Tsakiris, \& Haggard, 2008): body-ownership, the feeling that a body belongs to oneself (Aymerich-Franch \& Ganesh, 2015; Gallagher, 2000; Tsakiris, 2010); self-location, the volume in space where one feels to be located (Blanke \& Metzinger, 2009); and agency, which can be defined as "global motor control, including the subjective experience of action, control, intention, motor selection and the conscious experience of will” (Blanke \& Metzinger, 2009: 7). When users embody an avatar they experience ownership and agency of the avatar body (Kilteni, Groten, \& Slater, 2012), and self-location within its bodily boundaries (Lenggenhager, Tadi, Metzinger, \& Blanke, 2007; Slater, Perez-Marcos, Ehrsson, \& Sanchez-Vives, 2009). The illusion of ME is reported not only in human-looking avatars but also in non-human looking entities such as animals (Ahn et al., 2016) or robots with a highly robotic appearance (AymerichFranch, Petit, Ganesh, \& Kheddar, 2016, 2017a, 2017b).

Visual perspective and multisensory correlations are technically manipulated to induce the ME illusion. The use of head-mounted displays, which provide a first-person perspective from the avatar, and body-movement synchronization between the user and the avatar are used for this purpose (Fig. 1A). That said, multi-sensory correlations combined with a first-person perspective from the avatar are necessary conditions but not sufficient to induce the feeling of 
ME. In addition to the bottom-up multi-sensory perception, top-down perceptual processes regulate the illusion of ME. An experience of ME requires the central nervous system to incorporate the avatar "as a part of the bodily self, as belonging within rather than outside the boundaries of the body” (Haans \& Ijsselsteijn, 2012:215).

Likewise, during ME, people experience sense of presence (Lee, 2004) and respond to objects (Aymerich-Franch, et al., 2017a), virtual humans (Garau, Slater, Pertaub, \& Razzaque, 2005), and threats (Slater, Spanlang, Sanchez-Vives, \& Blanke, 2010) in the remote locations of their virtual and robotic avatars as if they were in their immediate, physical surroundings. Altogether, these findings provide strong evidence to support that, during experiences of mediated embodiment, the sense of self extends to the body of the avatar (Fig. 1B). Hence, the actual gravity of an offense to an avatar lies on the fact that an avatar is an alternative body for the "self."

\section{Implications of the extension of the self in mediated embodiment}

The expansion of immersive technologies capable of creating the illusion that an avatar is part of the self raises new legal and ethical challenges that need a prompt response (Fig. 1C). Given the recent development of mediated embodiment technologies, however, the literature lacks on studies addressing the intertwinement between robotic and virtual avatars, humans, and the law from a perspective that fully comprehends the consequences of embodying an avatar.

Mediated embodiment technologies may potentially fulfill daily needs ranging from providing a surrogate body to people with reduced mobility to providing digital surrogates for interpersonal relationships in virtual social networks. Notwithstanding these and other benefits, the use of avatars may bring about consequences that require close consideration. 
The 2017 report on online harassment by the Pew Research Center (2017) found that four-in-ten U.S. adults had experienced harassing or abusive behavior online and 18\% had been the target of severe offenses such as physical threats or sexual harassment. While the elevated number of cases of online harassment is a cause of concern per se, the psychological consequences for the victims of these offenses might dramatically increase if online gaming and communications implement embodiment technologies. Thus, an offense to an embodied avatar shall be of particular concern to developers and policymakers, as the extension of the sense of self to the avatar during experiences of ME implies that if the avatar gets harmed, the person who embodies that avatar gets harmed as well.

Mediated embodiment experiments (Aymerich-Franch et al., 2016, 2017a, 2017b; Slater et al., 2010) give compelling reasons to believe that avatars are an extension of the self, not a mere teleoperated robot or a virtual projection. This may challenge the ongoing legal discussion on the attribution of juridical personality to robots (Bryson, Diamantis, \& Grant, 2017) as the metaphors relating to electronic agent (Teubner, 2006), animal (Coeckelbergh, 2010), corporation or “digital peculium” (Pagallo, 2013) may not suit this case.

On this basis, the concept of property may also be called into question, as an embodied avatar will no longer be a simple property of the user, as the personal dwelling could be, but also his/her extended self to the virtual or robotic avatar. In light of psychological or physical harm to the avatar, the person embodied in it might also be psychologically affected regardless of the impassivity or insensitivity of the avatar.

\section{Avatars: a hybrid category “property-person”}

In legal terms, tampering with an object is considered, in essence, property damage. When these same facts affect a person, this is considered an offense against the person, which 
includes fatal (murder, manslaughter) and non-fatal offenses (assaults, injuries). Taking an object that is not yours is considered theft, but taking a person against his/her will is considered kidnapping or abduction. While the difference between property and person is clear within lawin-books, the progressive merge between users and avatars might easily blur such distinction.

An embodied avatar is not only a mere thing or a virtual projection, but a body to be in and interact with the world. Like the human body itself, this body contains the sense of self, and thus it constitutes an extension of the person. As well as trespassing is an interference with another person's legal property rights, but also constitutes assault or battery if such trespass is carried out against another person; interference with an embodied avatar may be constitutive of both at the same time. As the property and the person mingle in the avatar, avatar embodiment could, then, involve the constitution of a hybrid legal category (Fig. 1D). Hybrid categories emerge in response to complex interdependencies between different categories and to avoid legal lacunas. For instance, Internet-of-Things or automated systems are a hybrid product/service category due to their interdependency within products (hardware and software) and across interconnected devices (Evaluation of the Directive for Defective Products, 2018). Considering a property-person hybrid category in the case of ME may be instrumental in ensuring comprehensive legal protection to embodied users and in preventing developers from creating responsibility-free environments that serve as platforms for committing potential offenses.

We urge policymakers to carefully consider the policy and regulatory implications of mediated embodiment technologies, as we may be, as a society, interested in circumventing unfortunate scenarios before the society widely uses mediated embodiment technologies, especially if there are sufficient grounds to believe that these can have an impact on our-selves. 


\section{References}

Ahn, S. J. G., Bostick, J., Ogle, E., Nowak, K. L., McGillicuddy, K. T., \& Bailenson, J. N. (2016). Experiencing Nature: Embodying Animals in Immersive Virtual Environments Increases Inclusion of Nature in Self and Involvement With Nature. Journal of ComputerMediated Communication, 21(6), 399-419. http://doi.org/10.1111/jcc4.12173

Aymerich-Franch, L. (2018). Is mediated embodiment the response to embodied cognition? New Ideas in Psychology, 50, 1-5. http://doi.org/10.1016/j.newideapsych.2018.02.003

Aymerich-Franch, L., \& Ganesh, G. (2015). The role of functionality in the body model for selfattribution. Neuroscience Research. http://doi.org/10.1016/j.neures.2015.11.001

Aymerich-Franch, L., Petit, D., Ganesh, G., \& Kheddar, A. (2016). The second me: Seeing the real body during humanoid robot embodiment produces an illusion of bi-location. Consciousness and Cognition, 46, 99-109. http://doi.org/10.1016/j.concog.2016.09.017

Aymerich-Franch, L., Petit, D., Ganesh, G., \& Kheddar, A. (2017). Non-human Looking Robot Arms Induce Illusion of Embodiment. International Journal of Social Robotics, 9(4). http://doi.org/10.1007/s12369-017-0397-8

Aymerich-Franch, L., Petit, D., Ganesh, G., \& Kheddar, A. (2017). Object Touch by a Humanoid Robot Avatar Induces Haptic Sensation in the Real Hand. Journal of Computer-Mediated Communication, 22(4), 215-230. http://doi.org/10.1111/jcc4.12188

Blanke, O., \& Metzinger, T. (2009). Full-body illusions and minimal phenomenal selfhood. Trends in Cognitive Sciences, 13(1), 7-13. http://doi.org/10.1016/j.tics.2008.10.003

Bryson, J. J., Diamantis, M. E., \& Grant, T. D. (2017). Of, for, and by the people: the legal lacuna of synthetic persons. Artificial Intelligence and Law, 25(3), 273-291. 
http://doi.org/10.1007/s10506-017-9214-9

Coeckelbergh, M. (2010). Robot rights? Towards a social-relational justification of moral consideration. Ethics and Information Technology, 12(3), 209-221. http://doi.org/10.1007/s10676-010-9235-5

Evaluation of Council Directive 85/374/EEC on the approximation of laws, regulations and administrative provisions of the Member States concerning liability for defective products (2018). Retrieved from: https://publications.europa.eu/en/publication-detail//publication/d4e3e1f5-526c-11e8-be1d-01aa75ed71a1/language-en

Gallagher, I. (2000). Philosophical conceptions of the self: implications for cognitive science. Trends in Cognitive Sciences, 4(1), 14-21. Retrieved from http://www.ncbi.nlm.nih.gov/pubmed/10637618

Gallese, V., \& Sinigaglia, C. (2011). What is so special about embodied simulation? Trends in Cognitive Sciences, 15(11), 512-519. http://doi.org/10.1016/j.tics.2011.09.003

Garau, M., Slater, M., Pertaub, D., \& Razzaque, S. (2005). The responses of people to virtual humans in an immersive virtual environment, 14(1), 104-116. http://doi.org/10.1162/1054746053890242

Haans, A., \& Ijsselsteijn, W. A. (2012). Embodiment and telepresence: Toward a comprehensive theoretical framework. Interacting with Computers, 24(4), 211-218. http://doi.org/10.1016/j.intcom.2012.04.010

Kilteni, K., Groten, R., \& Slater, M. (2012). The Sense of Embodiment in Virtual Reality. Presence: Teleoperators and Virtual Environments, 21(4), 373-387. http://doi.org/10.1162/PRES_a_00124 
Lee, K. M. (2004). Presence, Explicated. Communication Theory, 14(1), 27-50. http://doi.org/10.1093/ct/14.1.27

Lenggenhager, B., Tadi, T., Metzinger, T., \& Blanke, O. (2007). Video ergo sum: manipulating bodily self-consciousness. Science (New York, N.Y.), 317(5841), 1096-9. http://doi.org/10.1126/science.1143439

Longo, M. R., Schüür, F., Kammers, M. P. M., Tsakiris, M., \& Haggard, P. (2008). What is embodiment? A psychometric approach. Cognition, 107(3), 978-98. http://doi.org/10.1016/j.cognition.2007.12.004

Pagallo, U. (2013). The laws of robots: Crimes, contracts, and torts. The Laws of Robots: Crimes, Contracts, and Torts. http://doi.org/10.1007/978-94-007-6564-1

Pew Research Center (2014) Online Harassment. Available at: http://www.pewinternet.org/2017/07/11/online-harassment-2017/ (accessed 26 August 2018)

Slater, M., Perez-Marcos, D., Ehrsson, H. H., \& Sanchez-Vives, M. V. (2009). Inducing illusory ownership of a virtual body. Frontiers in Neuroscience, 3(2), 214-20. http://doi.org/10.3389/neuro.01.029.2009

Slater, M., Spanlang, B., Sanchez-Vives, M. V, \& Blanke, O. (2010). First person experience of body transfer in virtual reality. PloS One, 5(5), e10564. http://doi.org/10.1371/journal.pone.0010564

Teubner, G. (2006). Rights of non-humans? Electronic agents and animals as new actors in politics and law. Journal of Law and Society, 33(4), 497-521. http://doi.org/10.1111/j.14676478.2006.00368.x 
Tsakiris, M. (2010). My body in the brain: a neurocognitive model of body-ownership. Neuropsychologia, 48(3), 703-12. http://doi.org/10.1016/j.neuropsychologia.2009.09.034 


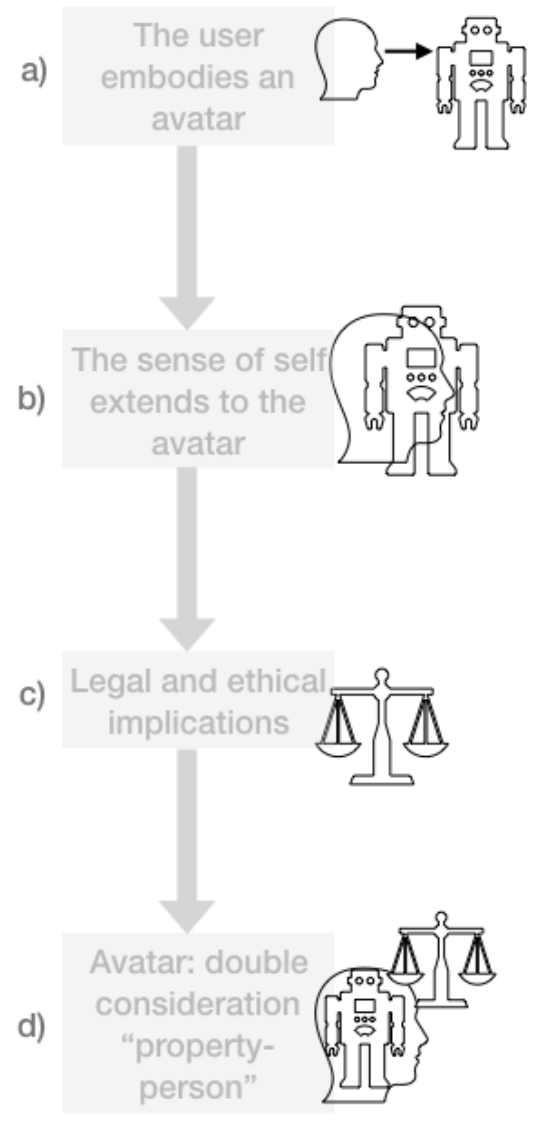

Figure 1. When people embody an avatar (a) their sense of self extends to the body of that avatar (b). This extension of the self entails important legal and ethical implications that policy makers need to address (c). The inclusion of avatars in a double category property-person might contribute to legally protect users of mediated embodiment experiences (d). 